\title{
A pH-responsive zinc (II) metalated porphyrin for enhanced photodynamic/photothermal combined cancer therapy
}

\author{
Pingping Liang ${ }^{1 \dagger}$, Hao Tang ${ }^{3 \dagger}$, Rui Gu ${ }^{1}$, Lei Xue ${ }^{1}$, Dapeng Chen ${ }^{1}$, Wenjun Wang ${ }^{2}$, Zhou Yang ${ }^{4^{*}}$, \\ Weili $\mathrm{Si}^{{ }^{*}}$ and Xiaochen Dong ${ }^{*}$
}

\begin{abstract}
The acidic tumor microenvironment is triggered by glycolysis in hypoxic condition, which can motivate the $\mathrm{pH}$ responsive system to build certain triggers for efficiently tumor-targeted phototherapy. Additionally, the metalated porphyrin structures are widely studied in biomedical applications due to the favorable properties of high singlet oxygen quantum yield as well as strong fluorescence imaging ability. Herein, a pH-responsive zinc (II) metalated porphyrin (P-4) was designed and synthesized for amplifying cancer photodynamic/photothermal therapy with excellent fluorescence quantum yield (67.4\%), superb singlet oxygen quantum yield $(84.3 \%)$ and desired photothermal conversion efficiency (30.0\%). In vitro, the self-assembled P-4 nanoparticles can specifically target to lysosome subcellular site and realize protonated process of dibutaneaminophenyl (DBAP) groups with high photo toxicity. Under single $660 \mathrm{~nm}$ laser illumination, the tumor can be ablated completely with no side effects in vivo. This work demonstrates that the $\mathrm{pH}$-responsive P-4 nanoparticles provide a new avenue for highly efficient cancer combination therapy.
\end{abstract}

Keywords: pH-responsive, porphyrin, NIR absorbance, photodynamic therapy, photothermal therapy

\section{INTRODUCTION}

Photodynamic therapy (PDT) has captured great notice in malignant cancer therapy, in which, the photosensitizer around the cancer cells can absorb light and transfer energy to the oxygen for producing reactive oxygen species (ROS), especially the singlet oxygen $\left({ }^{1} \mathrm{O}_{2}\right)$ to kill tumor cells $[1,2]$. On the other hand, photothermal therapy (PTT) agent can absorb light of specific wavelength and undergo non-radiative decay with heat release, resulting in irreversible cell damage, which has experienced explosive growth for cancer therapy in past decades [3]. However, for PDT, insufficient oxygen supply (hypoxia) $[4,5]$ and inadequate selectivity with prolonged skin photosensitization significantly impede the therapeutic effect [6,7]. For PTT, the up-regulated expression of heat shock proteins greatly decreases the treatment effect and limits its application in clinic [8-10]. Hence, to overcome these obstacles, combining two different therapeutic modalities, such as PDT and PTT, into one system to exceed the individual outcome is a favorable method to achieve improved anticancer therapy efficacy in recent years [11-13]. Nonetheless, most of the combined therapeutic agents are required to be excited by different lasers with two wavelengths because of the mismatched absorbance from photothermal and photosensitizer functional groups, resulting in longer therapeutic time and higher treatment cost [14-16].

Moreover, the short ${ }^{1} \mathrm{O}_{2}$ half-time $(<0.04 \mu \mathrm{s})$ with low diffusion depth $(<0.02 \mu \mathrm{m})[17,18]$, means that the targeted delivery of therapeutic agent to the tumor site is very important for the effective phototherapy [19]. In addition, the acidic tumor microenvironment (TME) is

\footnotetext{
${ }^{1}$ Key Laboratory of Flexible Electronics (KLOFE) \& Institute of Advanced Materials (IAM), Nanjing Tech University (NanjingTech), Nanjing 211800, China

${ }^{2}$ School of Physical Science and Information Technology, Liaocheng University, Liaocheng 252059, China

${ }^{3}$ Department of Pharmaceutical Preparation, Jinling Hospital, Nanjing 210002, China

${ }^{4}$ Beijing Key Laboratory of Function Materials for Molecule \& Structure Construction, School of Materials Science and Engineering, University of Science and Technology Beijing, Beijing 100083, China

$\dagger$ These authors contributed equally to this work.

* Corresponding authors (emails: iamxcdong@njtech.edu.cn (Dong X); iamwlsi@njtech.edu.cn (Si W); yangz@ustb.edu.cn (Yang Z))
} 
triggered by glycolysis in hypoxic condition. And the lysosome in tumor cells has a slightly acidic ( $\mathrm{pH}$ 4.5-5.0) environment compared with the cytoplasm ( $\mathrm{pH} 7.2$ ), which is kept by vacuolar-type $\mathrm{H}^{+}$-ATPase $[20,21]$. Therefore, in recent years, $\mathrm{pH}$-driven phototherapy agents have attracted significant interest to build certain triggers $[22,23]$. Unfortunately, most of these agents lack the selective localization in cancer cells or at tumor site, making the biological application incompatible $[22,24,25]$.

Motivated by all above, we designed and synthesized a pH-responsive zinc (II) metalated porphyrin (P-4) for amplifying cancer PDT/PTT (Scheme 1). In selfassembled P-4 nanoparticles (NPs), the central chromophore porphyrin can be activated to produce abundant singlet oxygen as well as strong fluorescence, and the dibutaneaminophenyl (DBAP) groups with $\mathrm{pH}$-responsive property can make the protonation in acidic TME for improving the ${ }^{1} \mathrm{O}_{2}$ quantum yield and photothermal conversion (PTC) efficiency. All experiments reveal the near-infrared (NIR) P-4 NPs targeting at lysosome subcellular site possess low dark toxicity, excellent phototoxicity in cancer cells, suggesting a desired photo ablation capability at tumor site via single laser illumination. Therefore, the as-prepared NPs can be potentially used as efficient agent for $\mathrm{pH}$-responsive cancer photodynamic and photothermal synergetic therapy in clinic.

\section{EXPERIMENTAL SECTION}

\section{Materials}

Fetal bovine serum (FBS), 3-(4,5-dimethyl-2-thiazolyl)2,5-diphenyl-2H-tetrazolium bromide (MTT) and other biological reagents were obtained from GIBCO. Green Lyso-Tracker, Mito-Tracker, ER-Tracker dyeing liquid and 4',6-diamidino-2-phenylindole (DAPI) were purchased from the Institute of Biochemistry and Cell Biology, Shanghai Institutes for Biological Sciences, Chinese Academy of Sciences (China). All other commercially available chemical agents were acquired from Sigma-Aldrich and used as received.

\section{Characterizations}

All the intermediate products and P-4 NPs were characterized by UV-vis-NIR spectrometer (Shimadzu, Japan), Fluorescence F-7000 spectrometer (HITACHI, Japan), ${ }^{1} \mathrm{H}$ NMR, ${ }^{13} \mathrm{C}$ NMR (Nuclear magnetic resonance, Bruker DRX NMR spectrometer), matrix-assisted laser desorption/ionization time-of-flight mass microscopy (MALDI-TOF MS, Bruker autoflex speed MALDI-TOF), dynamic light scattering (DLS, Malvern Zeta Sizer) and

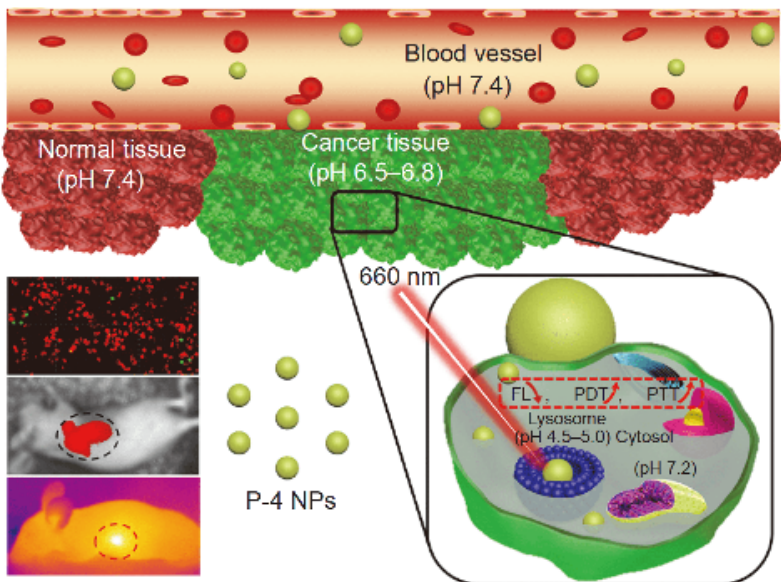

Scheme 1 Simplified representation of multi-imaging guided $\mathrm{pH}$-responsive cancer PTT/PDT in vitro and in vivo with P-4 NPs.

transmission electron microscopy (TEM, JEM-2010FEF). Other apparatus included confocal fluorescence microscope (Olympus IX 70), inverted fluorescence microscope (Nikon, Japan), Flow Cytometry System, IR thermal camera (FLIR System, Inc., Wilsonville, OR, USA), optical fiber coupled $660-\mathrm{nm}$ diode-laser and in vivo bioluminescence imaging system. All nude mice (five weeks aged, weight $18-20 \mathrm{~g}$ ) were gained from Comparative Medicine Centre of Yangzhou University. Sprague-Dawley (SD) rats with specific-pathogen-free (SPF) (body weight $220 \pm 10.0 \mathrm{~g}$ ) were obtained from the Animal Center of Nanjing Medical University (NJMU, Nanjing, China). All procedures were performed in strict accordance with the relevant institutional guidelines and laws.

\section{Synthesis of P-4}

4-Butoxybenzaldehyde (1.5 g), and dipyrromethane $(1.23 \mathrm{~g})$ were added in dichloromethane (DCM, $300 \mathrm{~mL})$ under $\mathrm{N}_{2}$ atmosphere to remove oxygen in ultrasonic cleaner for $30 \mathrm{~min}$. Next, trifluoroacetic acid (TFA, $0.5 \mathrm{~mL}$ ) was slowly injected in dark for $3 \mathrm{~h}$. Then 2,3dichloro-5,6-dicyano-1,4-benzoquinone (DDQ, $1 \mathrm{~g}$ ) was added for another $30 \mathrm{~min}$. At last, triethylamine $(10 \mathrm{~mL})$ was used to quench the reaction. The crude product was purified by chromatography on silica column (DCM/ petroleum ether $(\mathrm{PE}), V / V=1: 1)$ to obtain purple $\mathrm{P}-1$ (420 mg, yield: $8.7 \%) .{ }^{1} \mathrm{HNMR}\left(\mathrm{CDCl}_{3}, 400 \mathrm{MHz}\right): \delta$ $10.32(\mathrm{~s}, 2 \mathrm{H}), 9.41(\mathrm{~d}, J=3.6 \mathrm{~Hz}, 4 \mathrm{H}), 9.14(\mathrm{~d}, J=3.6 \mathrm{~Hz}$, $4 \mathrm{H}), 8.19(\mathrm{~d}, J=1.6 \mathrm{~Hz}, 4 \mathrm{H}), 7.36(\mathrm{~d}, J=3.6 \mathrm{~Hz}, 4 \mathrm{H}), 1.28$ (s, $18 \mathrm{H}),-3.05$ (s, 2H). MALDI-TOF MS: $\mathrm{m} / \mathrm{z}$ calcd. for $\mathrm{C}_{40} \mathrm{H}_{38} \mathrm{~N}_{4} \mathrm{O}_{2}$ 606.3; found 606.8.

P-1 (200 mg) and N-bromosuccinimide (NBS, $235 \mathrm{mg}$ ) 
were dissolved in DCM $(40 \mathrm{~mL})$ under $\mathrm{N}_{2}$ atmosphere to remove oxygen and reacted for $3 \mathrm{~h}$. Then, the solvent was distilled and the residue was purified on silica column $(\mathrm{DCM} / \mathrm{PE}, V / V=1: 1)$ to afford purple P-2 (240 $\mathrm{mg}$, yield: 95\%). ${ }^{1} \mathrm{HNMR}\left(\mathrm{CDCl}_{3}, 400 \mathrm{MHz}\right): \delta 9.63(\mathrm{~d}, J=3.6 \mathrm{~Hz}$, $4 \mathrm{H}), 8.90(\mathrm{~d}, J=3.6 \mathrm{~Hz}, 4 \mathrm{H}), 8.07(\mathrm{~d}, J=6.4 \mathrm{~Hz}, 4 \mathrm{H}), 7.32$ $(\mathrm{d}, J=6.4 \mathrm{~Hz}, 4 \mathrm{H}), 1.30(\mathrm{~m}, 18 \mathrm{H}),-2.68(\mathrm{~s}, 2 \mathrm{H})$. MALDITOF MS: $m / z$ calcd. for $\mathrm{C}_{40} \mathrm{H}_{36} \mathrm{Br}_{2} \mathrm{~N}_{4} \mathrm{O}_{2}$ 764.1; found 764.2.

P-2 $(240 \mathrm{mg})$ and zinc acetate $(58 \mathrm{mg})$ were mixed in DCM $(90 \mathrm{~mL})$ and methyl alcohol $(10 \mathrm{~mL})$ in dark to react for $3 \mathrm{~h}$. At last, the solvent was removed and the residue was purified on silica column (pure DCM) to achieve purple P-3 (267.7 mg, yield: 98\%). ${ }^{1} \mathrm{HNMR}$ $\left(\mathrm{CDCl}_{3}, 500 \mathrm{MHz}\right): \delta 10.22(\mathrm{~s}, 1 \mathrm{H}), 9.79(\mathrm{~d}, J=5.0 \mathrm{~Hz}$, $2 \mathrm{H}), 9.41(\mathrm{~d}, J=5.0 \mathrm{~Hz}, 2 \mathrm{H}), 9.09(\mathrm{~d}, J=5.0 \mathrm{~Hz}, 2 \mathrm{H}), 8.99$ (d, J=5.0 Hz, 2H), $8.02(\mathrm{~d}, J=10.0 \mathrm{~Hz}, 2 \mathrm{H}), 7.33(\mathrm{~d}$, $J=10.0 \mathrm{~Hz}, 2 \mathrm{H}), 1.28$ (m, 18H). MALDI-TOF MS: $\mathrm{m} / \mathrm{z}$

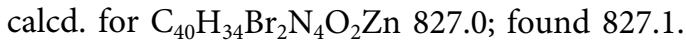

P-3 (50 mg), N,N-dibutyl-4-ethynylaniline (synthesized as described in the Supplementary information, $54 \mathrm{mg}$ ), trans-dichlorobis(triphenyl-phosphine)palladium(II) $(40 \mathrm{mg})$ and $\mathrm{CuI}(20 \mathrm{mg})$ were added in THF $(9 \mathrm{~mL})$ and triethylamine $(3 \mathrm{~mL})$ under $\mathrm{N}_{2}$ atmosphere in dark at $55^{\circ} \mathrm{C}$ for $6 \mathrm{~h}$. Last, the solvent was removed and the crude product was purified on silica column (DCM/ $\mathrm{PE}, V / V=1: 1)$ to attain deep green $\mathrm{P}-4(55 \mathrm{mg}$, yield: 82\%). ${ }^{1} \mathrm{H}$ NMR $\left(\mathrm{CDCl}_{3}, 400 \mathrm{MHz}\right.$ ) $\delta 9.73(\mathrm{~d}, J=4.6 \mathrm{~Hz}$, $4 \mathrm{H}), 8.92(\mathrm{~s}, 4 \mathrm{H}), 8.11(\mathrm{~d}, J=8.5 \mathrm{~Hz}, 4 \mathrm{H}), 7.82(\mathrm{~d}$, $J=8.8 \mathrm{~Hz}, 4 \mathrm{H}), 7.32(\mathrm{~d}, J=8.5 \mathrm{~Hz}, 4 \mathrm{H}), 6.76(\mathrm{~d}, J=8.9 \mathrm{~Hz}$, $4 \mathrm{H}), 4.31(\mathrm{t}, J=6.5 \mathrm{~Hz}, 4 \mathrm{H}), 3.42-3.35(\mathrm{~m}, 8 \mathrm{H}), 2.04-1.99$ (m, $4 \mathrm{H}), 1.75-1.64(\mathrm{~m}, 12 \mathrm{H}), 1.45(\mathrm{dd}, J=15.0,7.5 \mathrm{~Hz}$, $8 \mathrm{H}), 1.15(\mathrm{t}, J=7.4 \mathrm{~Hz}, 6 \mathrm{H}), 1.04(\mathrm{t}, J=7.4 \mathrm{~Hz}, 12 \mathrm{H})$ (Fig. S1); ${ }^{13} \mathrm{C} \mathrm{NMR}\left(\mathrm{CDCl}_{3}, 126 \mathrm{MHz}\right) \delta 158.92,151.97$, $150.06,148.85,148.27-148.11,135.43,134.63,132.96$, $132.33,130.73,122.23,112.73,111.55,109.72,90.55$, 68.06, 50.80, 31.61, 29.67, 20.37, 19.39, 13.99 (Fig. S2). MALDI-TOF MS: $m / z$ calcd. for $\mathrm{C}_{72} \mathrm{H}_{78} \mathrm{~N}_{6} \mathrm{O}_{2} \mathrm{Zn}$ 1,122.548; found 1,121.369 (Fig. S3).

\section{Preparation and characterizations of P-4 NPs}

P-4 NPs were acquired by the self-assembly method. Two milligram of P-4 (in $1 \mathrm{~mL}$ THF) was added into $10 \mathrm{~mL}$ of phosphate buffered solution (PBS, pH 7.4 and 5.0) at $25^{\circ} \mathrm{C}$. During this process, $\mathrm{P}-4$ molecules self-assembled into P-4 NPs. After self-assembling, THF was eliminated by nitrogen bubbling for $10 \mathrm{~min}$.

The microstructure of P-4 NPs was characterized by TEM, and particle sizes of the NPs were detected by DLS. The UV-vis-NIR and fluorescence spectrum data were measured by quartz cuvettes (optical path-length: $1 \mathrm{~cm}$ ) in wavelength range of $300-1,100 \mathrm{~nm}$ and $700-900 \mathrm{~nm}$, respectively.

For detection the fluorescence quantum yield of P-4 (in DCM), Indocyanine Green (ICG) in dimethyl sulfoxide $(\mathrm{DMSO})(\Phi F(\mathrm{~s})=0.13)$ was used as standard. The $\Phi F_{(\mathrm{X})}$ value was calculated by the following equation: $\Phi F_{(\mathrm{X})}=$ $\Phi F_{(\mathrm{S})} \times\left(A_{\mathrm{S}} / A_{\mathrm{X}}\right) \times\left(F_{\mathrm{X}} / F_{\mathrm{S}}\right) \times\left(n_{\mathrm{X}} / n_{\mathrm{S}}\right)^{2}$, where $A$ is the absorbance, $F$ is the area under the fluorescence emission curve, $n$ is the refractive index of the solvent, the subscripts $\mathrm{X}$ and $\mathrm{S}$ represent the sample and standard, respectively.

The singlet oxygen $\left({ }^{1} \mathrm{O}_{2}\right)$ generations of P-4 and P-4 NPs were measured via recording oxidation of diphenylisobenzofuran (DPBF, $2 \times 10^{-5} \mathrm{~mol} \mathrm{~L}^{-1}, 60 \mathrm{~s}$ ) and Singlet Oxygen Sensor Green (SOSG, $1.5 \mu \mathrm{g} \mathrm{m}^{-1}, 9 \mathrm{~min}$ ). The absorbance of DPBF at $416 \mathrm{~nm}$ and fluorescence intensity of SOSG at $531 \mathrm{~nm}$ were detected by UV-vis-NIR and fluorescence spectrophotometer with quartz cuvettes (optical path-length: $1 \mathrm{~cm}$ ), respectively. The ${ }^{1} \mathrm{O}_{2}$ quantum yield of P-4 was calculated by $\Phi_{\Delta(\mathrm{X})}=\Phi_{\Delta(\mathrm{MB})} \times$ $\left(S_{\mathrm{X}} / S_{\mathrm{MB}}\right) \times\left(F_{\mathrm{MB}} / F_{\mathrm{X}}\right)$, in which the subscripts $\mathrm{X}$ and $\mathrm{MB}$ represent the $\mathrm{P}-4$ and methylene blue, respectively. $F$ represents absorption correction factor calculated by $F=$ $1-10^{-\mathrm{OD}}$ (OD represents absorbance of the MB and P-4 at $442 \mathrm{~nm}) . S$ represents the slope of absorbance plot of DPBF $(416 \mathrm{~nm}) v s$. irradiation time.

Photothermal effect of P-4 NPs was detected by IR thermal camera to observe temperature changes. PBS dispersion of P-4 NPs was exposed to the laser $(660 \mathrm{~nm}$, $\left.0.8 \mathrm{~W} \mathrm{~cm}^{-2}\right)$ at different concentrations $(0,20,40,60$ and $80 \mu \mathrm{g} \mathrm{mL}^{-1}$ ) and different $\mathrm{pH}$ values (7.4 and 5.0) for $10 \mathrm{~min}$.

For assessing photo-stability of P-4 NPs, DLS morphology and UV-vis-NIR spectra before and after four cycles of heating ( $660 \mathrm{~nm}, 0.8 \mathrm{~W} \mathrm{~cm}^{-2}$, laser on: $5 \mathrm{~min}$ ) and cooling ( $660 \mathrm{~nm}, 0.8 \mathrm{~W} \mathrm{~cm}^{-2}$, laser off: $5 \mathrm{~min}$ ) were documented.

To evaluate the photothermal conversion (PTC) efficiency, PBS dispersion of P-4 NPs was irradiated under $660 \mathrm{~nm}$ laser $\left(0.8 \mathrm{~W} \mathrm{~cm}^{2}, 10 \mathrm{~min}\right)$. When the temperature reached a plateau, the laser was turned off. During the procedure, the real-time temperature change was recorded by IR thermal camera per $20 \mathrm{~s}$ in $20 \mathrm{~min}$. PBS of the same volume was also measured as control. The PTC efficiency $(\eta)$ was calculated by the following equation:

$\eta=\frac{h S\left(T_{\max }-T_{\text {surr }}\right)-Q_{0}}{I\left(1-10^{-A 660}\right)}$,

where, $h$ is the heat transfer coefficient; $S$ is the surface 
area of sample container; $T_{\max }$ is the steady-state maximum temperature; $T_{\text {surr }}$ is the ambient room temperature; $Q_{0}$ is the energy input after laser irradiation by the same solvent without NPs in the same condition. $h S$ and $Q_{0}$ were calculated by the following equations, respectively:

$\tau_{\mathrm{s}}=\frac{C_{\mathrm{d}} m_{\mathrm{d}}}{h S}$,

$Q_{0}=h S\left(T_{\max }-T_{\text {surr }}\right)$,

where, $\tau_{\mathrm{s}}$ is the sample-system time constant; $C_{\mathrm{d}}$ of deionized water is about $4.2 \mathrm{Jg} \mathrm{g}^{-1} \mathrm{k}^{-1} ; m_{\mathrm{d}}$ is the mass of the PBS dispersion.

\section{Cell culture and incubation condition}

HeLa cells were incubated at $37^{\circ} \mathrm{C}$ in Dulbecco's Modified Eagle's Medium (DMEM), including 10\% inactivated FBS and $1 \%$ double resistant (penicillin and streptomycin) under $95 \%$ air and 5\% $\mathrm{CO}_{2}$ atmosphere humidified condition.

\section{In vitro cell cytotoxicity}

After incubation of the HeLa cells with fresh medium containing different concentrations of P-4 NPs $(0,4,8$, 12 , and $16 \mu \mathrm{g} \mathrm{mL}^{-1}$ ) in 96 well plates for $24 \mathrm{~h}$, one plate was irradiated with laser $\left(660 \mathrm{~nm}, 0.8 \mathrm{~W} \mathrm{~cm}^{-2}, 8 \mathrm{~min}\right.$ ) and the other was still kept in dark. After $12 \mathrm{~h}$, the MTT solution $\left(5 \mathrm{mg} \mathrm{mL}^{-1}, 20 \mu \mathrm{L}\right)$ was added to per well for $4 \mathrm{~h}$. Then DMSO (150 $\mu \mathrm{L}$ per well) was added to dissolve the purple formazan. At last, the absorbance was detected via a microplate reader at $492 \mathrm{~nm}$. Cell viability values were calculated by: cell viability $(\%)=($ absorbance of experimental group/absorbance of control group) $\times 100 \%$.

\section{Apoptosis study by flow cytometry}

After incubation of the HeLa cells with fresh medium containing different concentrations of P-4 NPs $(0,4,10$ and $16 \mu \mathrm{g} \mathrm{mL}^{-1} \mathrm{P}-4 \mathrm{NPs}$ ), all the cells were irradiated by $660 \mathrm{~nm}$ laser $\left(0.8 \mathrm{~W} \mathrm{~cm}^{-2}, 8 \mathrm{~min}\right)$. and stained with propidium iodide and annexin V-FITC. At last, all samples were detected by flow cytometer.

\section{AM/PI staining}

The P-4 NPs incubated HeLa cells in two groups (0 and $\left.16 \mu \mathrm{g} \mathrm{mL}^{-1}\right)$ were irradiated by $660 \mathrm{~nm}$ laser $\left(0.8 \mathrm{~W} \mathrm{~cm}^{-2}\right.$, $10 \mathrm{~min}$ ) and stained with AM/PI (AM: $2 \mu \mathrm{mol} \mathrm{L}^{-1}$, PI: $8 \mu \mathrm{mol} \mathrm{L}^{-1}$ ). Then fluorescence images were acquired via an inverted fluorescence microscope to detect the living and dead cells (AM excited at $465 \mathrm{~nm}$, PI excited at
$533 \mathrm{~nm})$.

\section{In vitro cellular uptake of P-4 NPs}

After incubation of the HeLa cells with fresh medium containing $10 \mu \mathrm{g} \mathrm{mL}^{-1} \mathrm{P}-4$ NPs in PBS (pH 7.4 and 5.0) dispersion in dark for $24 \mathrm{~h}$ (called this method as $\mathrm{A}$ ), the cells were incubated with $4 \%$ paraformaldehyde for $20 \mathrm{~min}$ and washed by PBS. After being stained with DAPI for 3 min and rinsed with PBS thrice, the two plates were refilled for with PBS (1 mL, pH 7.4 and 5.0, respectively). The fluorescence images were measured by a laser scanning up-conversion luminescence microscope equipped (excited at $633 \mathrm{~nm}$ ).

\section{Intracellular ROS assay and sub-cellular localization}

HeLa cells were incubated as above method (A). For ROS assay, all the cells were operated in $2^{\prime}, 7^{\prime}$-dichlorodihydrofluorescein diacetate (DCFH-DA) for $25 \mathrm{~min}$, paraformaldehyde (4\%) for $20 \mathrm{~min}$ and DAPI for $3 \mathrm{~min}$ in dark. After being washed thrice with PBS ( $\mathrm{pH}$ 7.4), the plate was refilled with PBS $(1 \mathrm{~mL}, \mathrm{pH} 7.4)$ and irradiated with $660 \mathrm{~nm}$ laser $\left(0.8 \mathrm{~W} \mathrm{~cm}^{-2}, 8 \mathrm{~min}\right)$. For sub-cellular localization assay, cells were respectively incubated with Green Lyso-Tracker, Mito-Tracker and ER-Tracker liquid dyes. At last, cell images were recorded with the laser scanning up-conversion luminescence microscope equipped (DCF excited at $488 \mathrm{~nm}, \mathrm{P}-4 \mathrm{NPs}$ and Green Trackers excited at $633 \mathrm{~nm}$ ).

\section{In vivo fluorescence imaging}

The nude mice were anaesthetized with oxygen flow with $2 \%$ isoflurane $\left(2 \mathrm{~L} \mathrm{~min}^{-1}\right)$ during imaging. And the contrast imaging at different time $(0,2,6,12,24$ and $48 \mathrm{~h})$ were acquired via the fluorescence imaging system (excited at $660 \mathrm{~nm}$ ). Afterwards, the mice were sacrificed by cervical dislocation. At last, major organs (tumor, heart, liver, spleen, lung and kidneys) were collected and imaged on the same imaging equipment.

\section{Pharmacokinetics}

Six SD rats with specific-pathogen-free (SPF) (three males and three females) were fasted for $12 \mathrm{~h}$, and given P-4 NPs via intravenous injection at a dose of $3 \mathrm{mg} \mathrm{kg}^{-1}$. The venous blood sample $(500 \mu \mathrm{L})$ was drawn from the orbit of rats at $0,0.083,0.167,0.25,0.5,1,2,4,6,8,12 \mathrm{~h}$ after intravenous administration. Plasma was separated from the whole blood by centrifugation at 3,000 $\times \mathrm{g}$ for $10 \mathrm{~min}$ at $4^{\circ} \mathrm{C}$ and stored at $-80^{\circ} \mathrm{C}$ until ultraviolet spectrophotometer analysis. And the pharmacokinetic parameters were calculated by non-compartmental method 
using DAS (Drug and Statistics) 2.0 software (Mathematical Pharmacology Professional Committee of China, Shanghai, China). The area under the concentration-time curve (AUC) from zero to the last measurable plasma concentration point $\left(\mathrm{AUC}_{0-t}\right)$, AUC from 0 to infinity $\left(\mathrm{AUC}_{0-\infty}\right)$, terminal elimination half-life $\left(t_{1 / 2}\right)$, mean residence time (MRT), and clearance (CL) were calculated systematically.

\section{In vivo antitumor assay}

Subcutaneous cells injection $\left(5 \times 10^{6}\right.$ cells in $200 \mu \mathrm{L}$ PBS) under forelimb method was used to obtain the HeLa tumor-bearing nude mice models. All mice were carefully looked after and randomly separated into three groups ( $n=6$, saline+laser, P-4 only and P-4+laser) in ventilated cages when the tumor volumes reached about 130$150 \mathrm{~mm}^{3}$. And the antitumor assay was operated with $0.4 \mathrm{mg} \mathrm{kg}^{-1}$ dosage of P-4 NPs for $10 \mathrm{~min}$ laser illumination $\left(660 \mathrm{~nm}, 0.8 \mathrm{~W} \mathrm{~cm}^{-2}\right)$ every two days. The body weights and tumor volumes $\left(V=0.5 a b^{2}, a\right.$ : the largest superficial diameter; $b$ : the smallest superficial diameter) were measured via digital scale and caliper.

\section{Histology sample preparation}

After 18 days treatment, to obtain the tumors and major organs (heart, liver, spleen, lung and kidney), all HeLa tumor-bearing nude mice were killed for histological analysis via haematoxylin and eosin (H\&E) staining. At last, all samples were imaged with microscopy.

\section{RESULTS}

\section{Synthesis and characterization}

Scheme S1 shows the synthetic process for P-4. 4-Butoxybenzaldehyde reacted with dipyrromethane to give purple P-1. Bromination of P-1 in the presence of $N$ bromosuccinimide occurred to afford purple P-2. Then P-3 was obtained by the reaction between P-2 and zinc acetate. At last, P-3 reacted with $N, N$-dibutyl-4-ethynyl aniline to attain deep green $\mathrm{P}-4$ in a high yield of $82 \%$. ${ }^{1} \mathrm{H}$ NMR, ${ }^{13} \mathrm{C}$ NMR and MALDI-TOF MS (Figs S1-S3) were used to characterize all intermediates and P-4.

With the addition of $\mathrm{CF}_{3} \mathrm{COOH}$ (TFA), $\mathrm{H}^{+}$can bond to $\mathrm{pH}-$ responsive DBAP groups in $\mathrm{P}-4$, resulting in a series of changes, including solution color, absorbance and emission spectra. As shown in Fig. 1a, P-4 can be protonated to form $\mathrm{P}-41 \mathrm{H}$ and $\mathrm{P}-42 \mathrm{H}$ via gradually adding TFA. During this process, light green $\mathrm{P}-4$ solution turned into brownish green $(\mathrm{P}-41 \mathrm{H})$ and brown $(\mathrm{P}-42 \mathrm{H})$, exhibiting a sensitive $\mathrm{pH}$-responsive performance (Fig. 1b). As shown in Fig. 1c, P-4 exhibits characteristic absorption peaks at 471 and $674 \mathrm{~nm}$, then blue-shift of the absorbance can be observed along with TFA addition due to the gradual protonation. Moreover, in corresponding emission spectrum (Fig. 1d), the characteristic emission peak of P-4 at $697 \mathrm{~nm}$ gradually blue-shifts and weakens, a

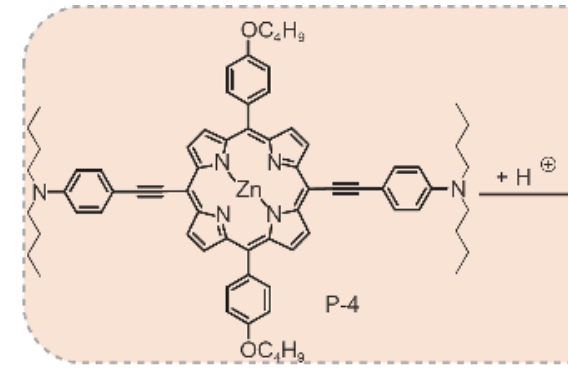

b

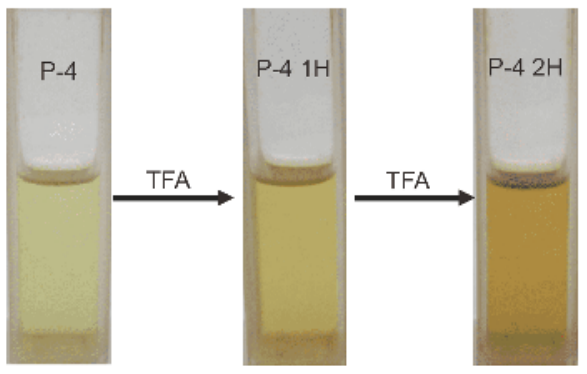

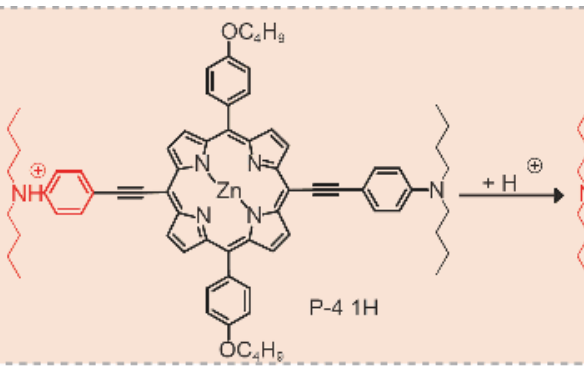
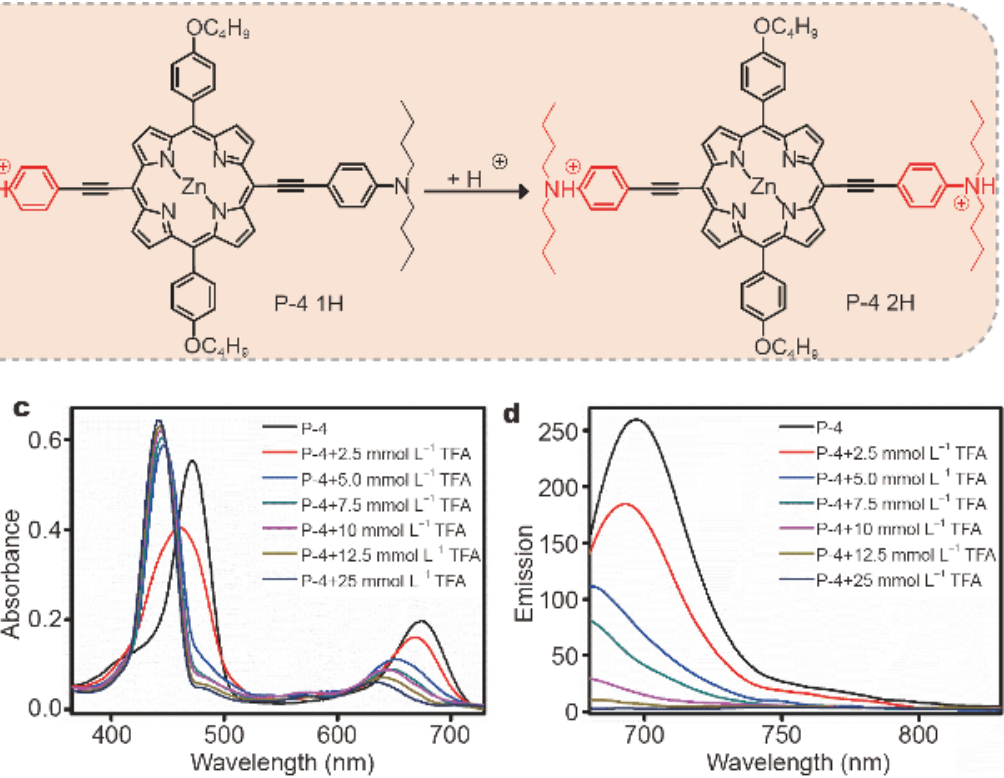

Figure 1 (a) Proposed protonation mechanism of $\mathrm{P}-4$ triggered by $\mathrm{H}^{+}$. (b-d) Color, absorbance and emission changes of $\mathrm{P}-4$ solution (in DCM) with TFA addition. 
which is attributed to the sequential protonation process as well, resulting in more energy delivering to non-radiative transition and intersystem crossing. All these experiments prove the $\mathrm{pH}$-responsive behavior of $\mathrm{P}-4$.

A simple self-assembly method was used to prepare the hydrophilic P-4 NPs [26]. When compared with P-4, Fig. 2a displays that P-4 NPs can superbly disperse in PBS. And the TEM image shows that P-4 NPs possess welldefined spherical structure at both $\mathrm{pH} 7.4$ and 5.0. In addition, the DLS measurement suggests the NPs present narrow size distribution with average sizes $46 \pm 2 \mathrm{~nm}(\mathrm{pH}$ 7.4) and $68 \pm 2 \mathrm{~nm}$ (pH 5.0) (Fig. 2b and Fig. S4a), which will promote the enhanced permeability and retention (EPR) effect. Furthermore, P-4 NPs exhibit a NIR absorbance band at $693 \mathrm{~nm}\left(\lambda_{\max }\right)$, demonstrating slight red- shift $(8 \mathrm{~nm})$ compared with P-4 (Fig. 2c). It is attributed to the intermolecular and intramolecular $\pi-\pi$ stacking of $\mathrm{P}-4$, making P-4 NPs as the desired candidate for cancer phototherapy. Moreover, excellent molar extinction coefficient $(\varepsilon)$ of P-4 NPs at $693 \mathrm{~nm}$ was $2.05( \pm 0.2) \times$ $10^{4}\left(\mathrm{~mol} \mathrm{~L}^{-1}\right)^{-1} \mathrm{~cm}^{-1}(A=\varepsilon c L)$ (Fig. 2d, Fig. S4b), proving the excellent light-absorbing capacity of the NPs. Additionally, emission peaks of P-4 and P-4 NPs (pH 7.4) are 703 and $714 \mathrm{~nm}$, respectively (Fig. S4c). Besides, the emission peak of P-4 NPs (pH 5.0) is weak and blue-shift compared with that at $\mathrm{pH} 7.4$ (Fig. S4d), which is consistent with the result in organic phase. At last, the fluorescence quantum yield (ICG as reference) was calculated to be $67.4 \%$, implying the bioimaging capability of P-4 NPs ( $\mathrm{pH}$ 7.4) for cancer phototherapy.
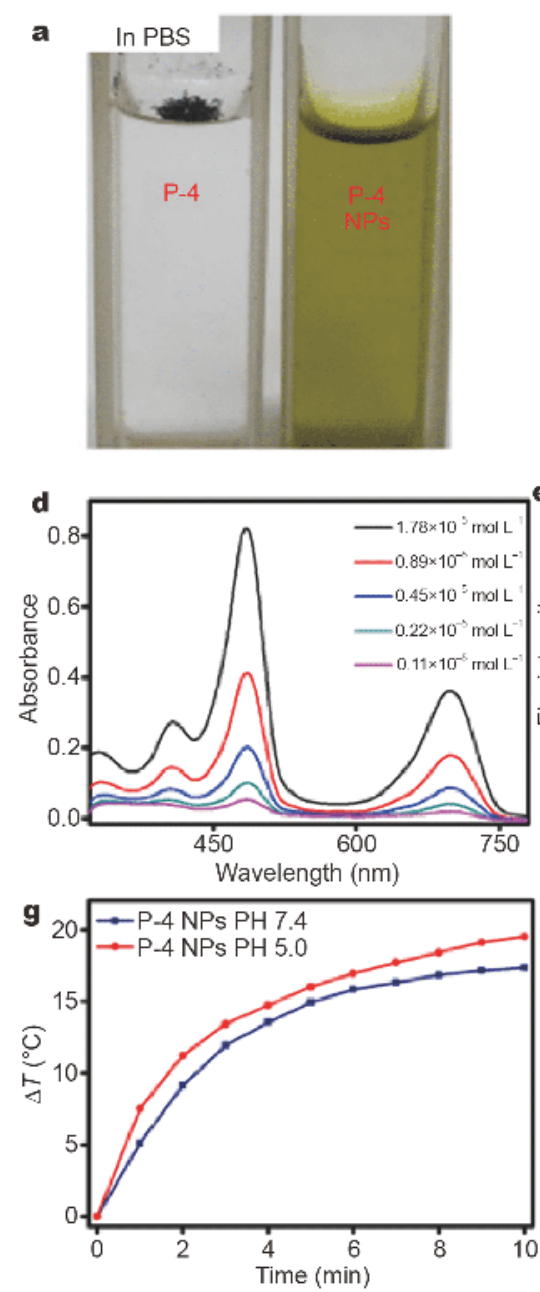

b
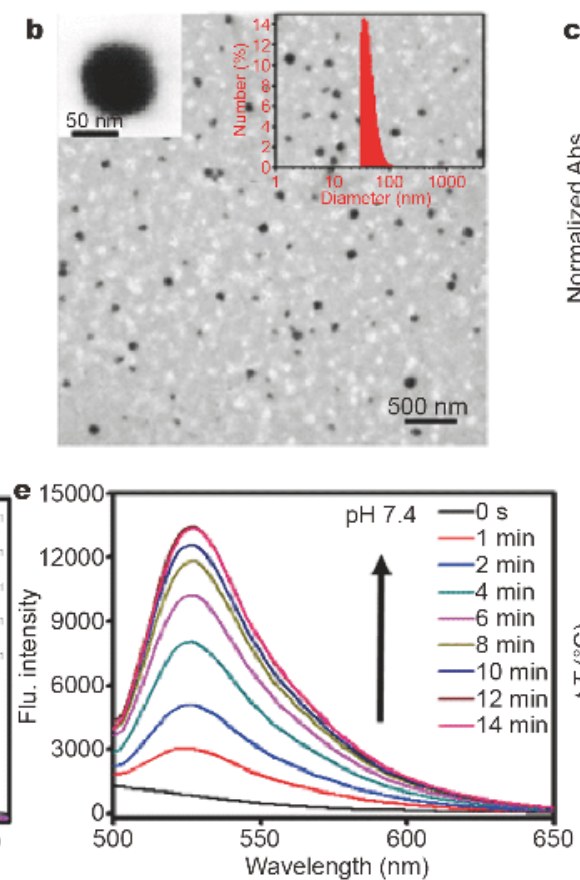

h

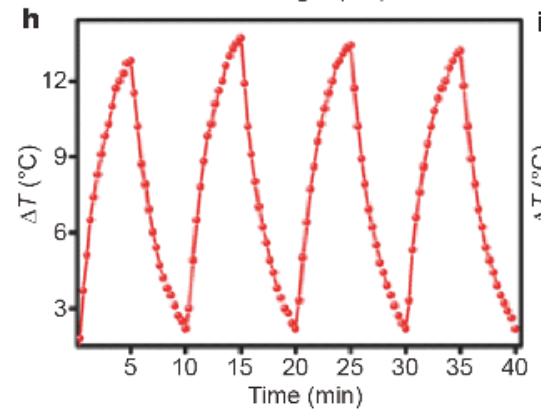

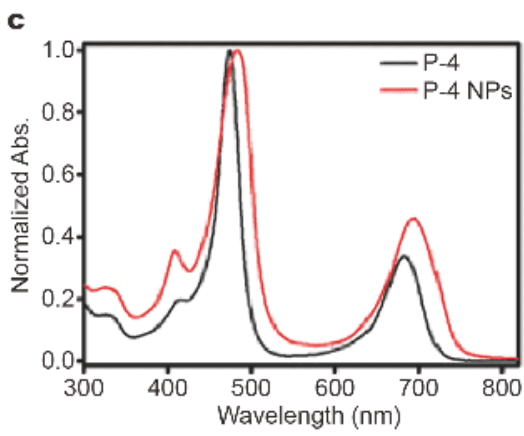
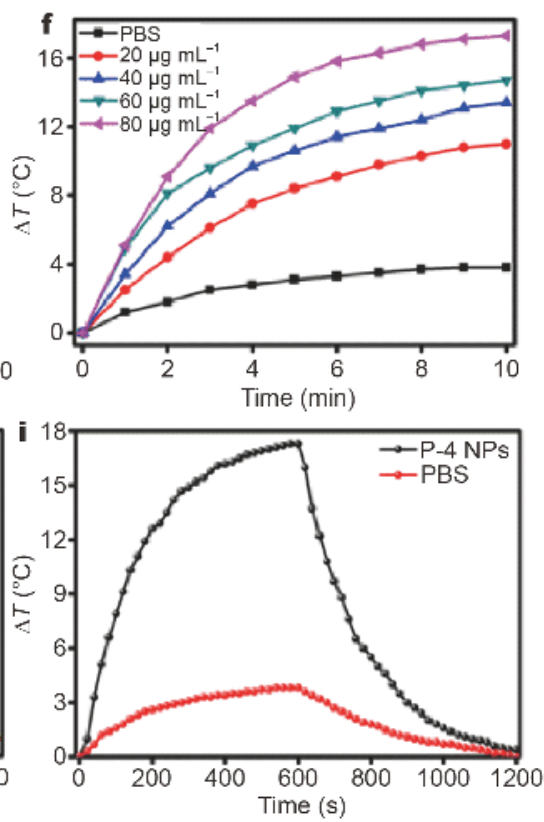

Figure 2 (a) Photographs of P-4 and P-4 NPs. (b) TEM image of P-4 NPs (pH 7.4), inset: DLS size distribution. (c, d) Absorbance of P-4 and P-4 NPs at different concentrations. (e) Fluorescence spectra of SOSG mixed with P-4 NPs (pH 7.4). (f, g) Photothermal curves of P-4 NPs at different concentrations and $\mathrm{pH}$. (h) Heating and cooling curves of P-4 NPs $\left(80 \mu \mathrm{g} \mathrm{m}^{-1}\right)$ for four cycles $\left(660 \mathrm{~nm}, 0.8 \mathrm{~W} \mathrm{~cm}{ }^{-2}\right)$. (i) Photothermal curve of P-4 NPs $\left(0.5 \mathrm{~mL}, 80 \mu \mathrm{g} \mathrm{mL}^{-1}\right)$ during laser on and off $\left(660 \mathrm{~nm}, 0.8 \mathrm{~W} \mathrm{~cm}^{-2}\right.$, control: PBS). 


\section{pH-responsive performance}

Singlet oxygen $\left({ }^{1} \mathrm{O}_{2}\right)$ generation ability was measured by DPBF probe with TFA acidity regulator [27]. The absorbance of DPBF mixed with P-4 at low $\mathrm{pH}$ (with $25 \mathrm{mmol} \mathrm{L}^{-1}$ TFA) declined more rapidly with an irradiation time dependence compared with the groups of DPBF only and DPBF mixed with P-4 in neutral condition (Fig. S5a-d), which indicates an acidity-dependent ${ }^{1} \mathrm{O}_{2}$ generation ability of $\mathrm{P}-4$. And compared with methylene blue reference $(\mathrm{MB}, \Phi \Delta=0.52$ ), the $84.3 \%$ (at low pH with 25 mmol L ${ }^{-1}$ TFA) ${ }^{1} \mathrm{O}_{2}$ quantum yield of $\mathrm{P}-4$ is also much higher than that of $\mathrm{MB}$ and most reported agents $[28,29]$. Furthermore, the ${ }^{1} \mathrm{O}_{2}$ generation ability of P-4 NPs was also detected via indicator of $1.5 \mu \mathrm{g} \mathrm{mL}^{-1}$ SOSG [30]. As displayed in Fig. 2e ( $\mathrm{pH} \mathrm{7.4),} \mathrm{the} \mathrm{fluor-}$ escence of SOSG shows a steady increase with $660 \mathrm{~nm}$ laser illumination (at $531 \mathrm{~nm}$, mixed with P-4 NPs), and $\mathrm{P}-4 \mathrm{NPs}$ at $\mathrm{pH} 5.0$ (Fig. $\mathrm{S} 4 \mathrm{e}$ ) present a stronger ${ }^{1} \mathrm{O}_{2}$

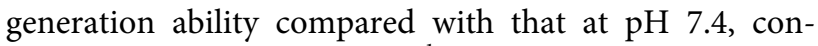
firming the acidity-activated ${ }^{1} \mathrm{O}_{2}$ generation of P-4 NPs. Encouraged by the NIR absorbance of P-4 NPs, PTC ability of P-4 NPs ( $\mathrm{pH} 7.4$ ) was recorded via laser illumination $\left(0.8 \mathrm{~W} \mathrm{~cm}^{-2}\right)$ for $10 \mathrm{~min}$ at different dispersion concentrations. Fig. $2 \mathrm{f}$ displays that the respective temperature increase is about $3.8,11.0,13.4,14.7$, and $17.3^{\circ} \mathrm{C}$ (from 0 to $80 \mu \mathrm{g} \mathrm{mL}^{-1}$ ), presenting obvious concentration dependence and excellent photothermal effect of P-4 NPs. Meanwhile, the temperature increase $\left(19.5^{\circ} \mathrm{C}\right)$ of P-4 NPs $\left(80 \mu \mathrm{g} \mathrm{mL}^{-1}\right)$ at $\mathrm{pH} 5.0$ was also studied, which was superior than that of $17.3^{\circ} \mathrm{C}(\mathrm{pH} 7.4)$ under the same condition, exhibiting a $\mathrm{pH}$-responsive photothermal effect of P-4 NPs (Fig. $2 \mathrm{~g}$ ). To verify the stability of P-4 NPs in water, the Zeta potential was measured as $-18.72 \mathrm{mV}$ (Fig. S4g). Besides, Fig. 2h confirms that the temperature promotion of P-4 NPs has no decline after four periodic laser illumination cycles (on and off: respective $5 \mathrm{~min}$ ), and the absorbance spectrum and size measurements of P-4 NPs exhibit no obvious changes (Fig. S5e, f). All these results indicate the excellent photostability of P-4 NPs. At last, the PTC efficiency was analyzed to be $30.0 \%$ ( $\mathrm{pH} 7.4$, Fig. $2 \mathrm{i}$ and Fig. S4f), which was better than that of some traditional inorganic agents, such as $\mathrm{Fe}_{3} \mathrm{O}_{4} @ P D A-5$ (13.1\%) and $\mathrm{Cu}_{9} \mathrm{~S}_{5}(25.7 \%)$ [31,32]. And the individually PDT and PTT effects as controls can refer to our group's previous work [33].

\section{In vitro examinations}

The dark toxicity and photo-toxicity of P-4 NPs to HeLa cells in vitro were studied via MTT assay. As demonstrated in Fig. 3a, P-4 NPs possess superb biocompat- ibility even at $16 \mu \mathrm{g} \mathrm{mL}^{-1}$ in dark and excellent phototoxicity with low half maximal inhibitory concentration $\left(\mathrm{IC}_{50}\right)$ of $10 \mu \mathrm{g} \mathrm{mL}^{-1}$ by illumination. Besides, the flowcytometric experiment was further carried out to quantitatively test the apoptosis at different stages triggered by P-4 NPs. As exhibited in Fig. 3b, the HeLa cell apoptosis rate is $6.7 \%, 31.1 \%, 49.9 \%$ and $75.2 \%$, respectively, with a dose-dependence. Based on the superb PTT/PDT effect of P-4 NPs in a cellular microenvironment, the PTT toxicity alone (at room temperature) was explored by quenching the ROS with $\mathrm{N}$-acetyl-L-cysteine (NAC, cell viability: 0.61 ) and PDT toxicity alone by maintaining the temperature of media at $4^{\circ} \mathrm{C}$ (cell viability: 0.78 ). For the synergistic PTT/PDT group, the cell viability is only 0.51 . However, for the NAC + ice $\left(4^{\circ} \mathrm{C}\right)$ group, the cell viability is around 0.94 (Fig. S6a, $660 \mathrm{~nm}$ laser, $0.8 \mathrm{~W} \mathrm{~cm}{ }^{-2}, 5 \mathrm{~min}$, $\left.\mathrm{IC}_{50}=10 \mu \mathrm{g} \mathrm{mL}^{-1}\right)$. At last, calcein-AM/PI co-staining was performed with HeLa cells to further observe the live (green) and dead (red) cells after $660 \mathrm{~nm}$ laser illumination.

Fig. 3c proves more dead cells after incubation with P-4 NPs compared with the control group (without P-4 NPs, Fig. 3d). All these results demonstrate that the P-4 NPs display high photo-ablation ability. Cellular uptake assay of P-4 NPs was executed after the P-4 NPs incubation using fluorescent confocal microscope. Cells in $\mathrm{pH} 7.4$ present more obvious fluorescence than that in $\mathrm{pH} 5.0$ (Fig. 4a), which implies that fluorescent radiation decay is declined in acidic TME. In addition, based on the superb ${ }^{1} \mathrm{O}_{2}$ generation capacity of P-4 and P-4 NPs in solvent, the ${ }^{1} \mathrm{O}_{2}$ generation capability was also estimated in vitro using DCFH-DA (excited at $633 \mathrm{~nm}$ ) as ROS probe. The bright green fluorescence in cytoplasm reveals that P-4 NPs display desired ${ }^{1} \mathrm{O}_{2}$ generation capability in cancer cells (Fig. 4b). Furthermore, the subcellular localization experiment of P-4 NPs in HeLa cells was carried out by Green subcellular trackers. Fig. 4c presents the clear orange yellow color in the lysosomes, due to the fluorescence overlaps of green (Lyso-Tracker) and red (P-4 NPs). And the Pearson's correlation coefficient (PCC) for P-4 NPs and Lyso-Tracker channel was calculated to be 0.81 , which was much higher than that for P-4 NPs and Mito-Tracker channel (0.45). It indicates the NPs can be mainly pumped into lysosomes ( $\mathrm{pH} 4.5-5.0)$ via vasculartype $\mathrm{H}^{+}$-ATPase [20], which will trigger the improved phototherapy under acidic TME.

\section{In vivo examinations}

Based on the superb properties of P-4 NPs in vitro, a series of in-vivo experiments were implemented. At first, the fluorescence imaging of P-4 NPs was observed with 
a
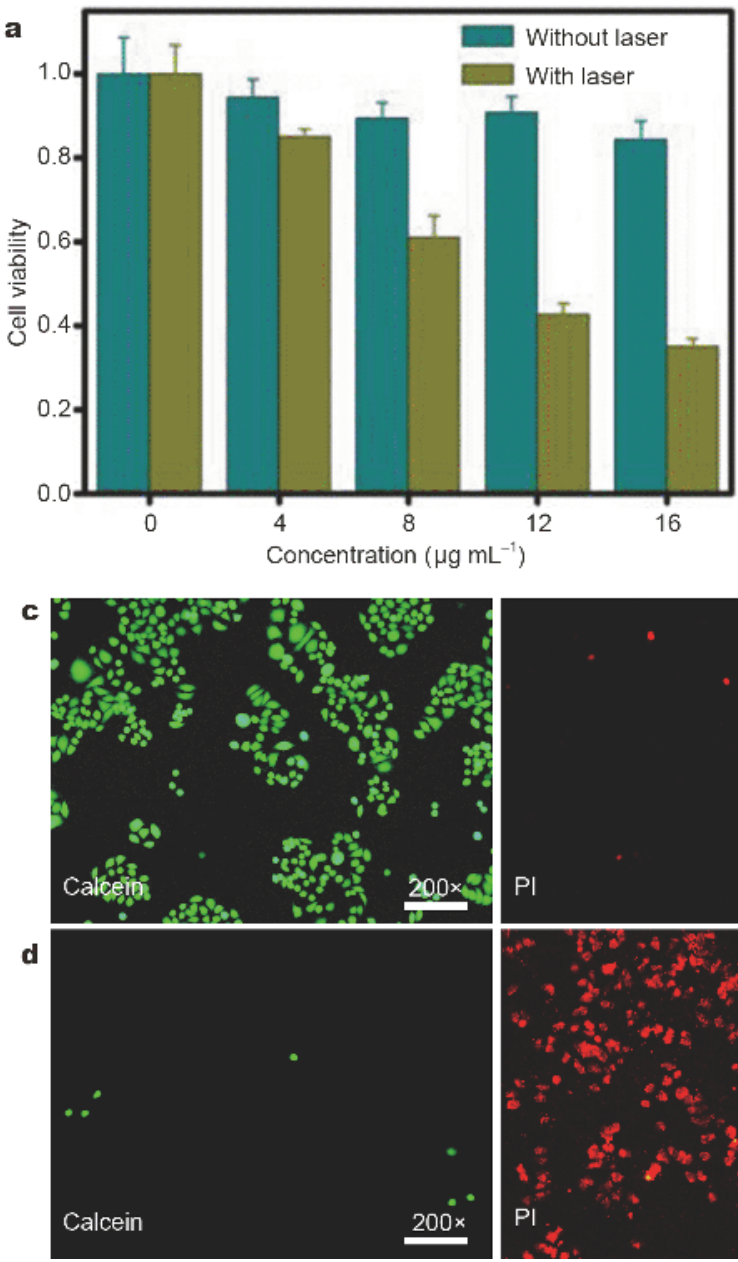

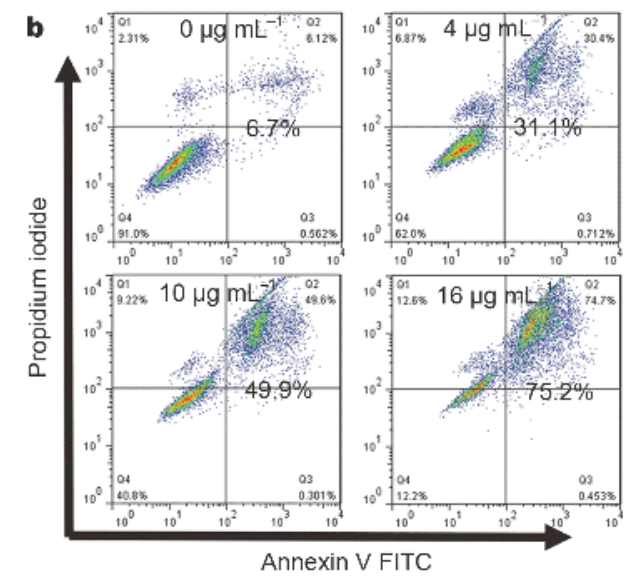

Annexin $V$ FITC
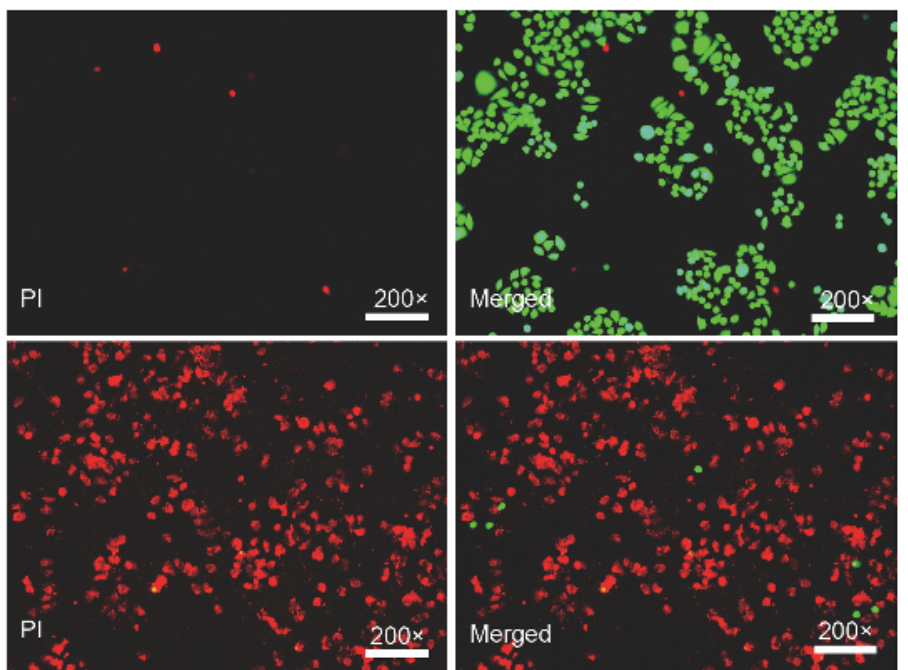

Figure 3 (a, b) MTT and flow cytometry assays $\left(660 \mathrm{~nm}, 8 \mathrm{~min}, 0.8 \mathrm{~W} \mathrm{~cm}^{-2}\right)$. (c, d) Fluorescence images $(200 \times)$ of calcein-AM/PI co-staining HeLa cells incubated without and with P-4 NPs $\left(660 \mathrm{~nm}, 10 \mathrm{~min}, 0.8 \mathrm{~W} \mathrm{~cm}^{-2}, 16 \mu \mathrm{g} \mathrm{mL}^{-1}\right)$.

HeLa tumor-bearing nude mice. As presented in Fig. 5a, after the intravenous injection, fluorescence intensity steadily increased to maximum at $12 \mathrm{~h}$, then decreased because of the metabolism of P-4 NPs, which will guide the cancer phototherapy in vivo on time window. Besides, the fluorescence of tumor and organs (spleen, kidney, lung, heart and liver) indicates the tumor and liver exhibit stronger fluorescence than other organs, which can further confirm that most of the NPs accumulate at tumor site via EPR effect. Then the liver is a detoxifying organ, demonstrating the desired metabolizable property of P-4 NPs in vivo. Additionally, photothermal imaging at tumor site was performed at $12 \mathrm{~h}$ intravenous injection with $660 \mathrm{~nm}$ laser irradiation $\left(0.8 \mathrm{~W} \mathrm{~cm}^{-2}\right)$. Fig. $5 \mathrm{~b}$ proves that the temperature at tumor site gradually rose to $51.6^{\circ} \mathrm{C}$ $\left(\Delta T=15.4^{\circ} \mathrm{C}\right)$, but little temperature increased $(\Delta T=$ $3.7^{\circ} \mathrm{C}$ ) in the control group was observed within $8 \mathrm{~min}$, which also verifies the superb tumor targeted accumulation and photothermal imaging effect of P-4 NPs for cancer phototherapy in vivo. Moreover, the pharmacokinetics of P-4 NPs was studied through the sensitive and specific ultraviolet spectrophotometer after intravenous injection. The mean plasma concentration-time profiles of P-4 NPs are shown in Fig. S7a. And the major pharmacokinetic parameters are presented in Table S1, which were calculated by a non-compartmental model. The ratio of $\mathrm{AUC}_{0-t} / \mathrm{AUC}_{0-\infty}$ was more than $80 \%$, suggesting the blood collection time point was suitable for the pharmacokinetic studies. The data shows that the P-4 NPs were eliminated quickly, with a $t_{1 / 2}$ of $1.203 \pm 0.038 \mathrm{~h}$. The MRT and CL of P-4 NPs was $0.848 \pm 0.0515 \mathrm{~h}$ and $0.176 \pm 0.0145 \mathrm{~L} \mathrm{~h}^{-1} \mathrm{~kg}^{-1}$, respectively.

Finally, the amplifying cancer phototherapy of $\mathrm{pH}$ responsive P-4 NPs was carried out by $18 \mathrm{HeLa}$ tumor- 

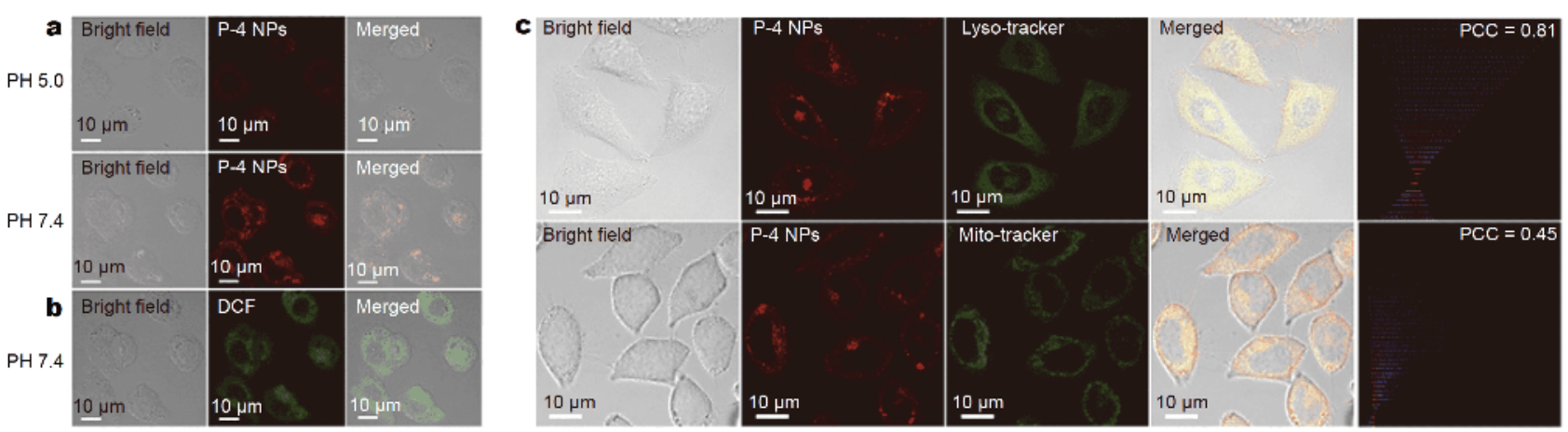

Figure $4(\mathrm{a}, \mathrm{b})$ Confocal fluorescence images of HeLa cells incubated with P-4 NPs $\left(10 \mu \mathrm{gL}^{-1}\right)$ and DCFH-DA after laser illumination. (c) Subcellular localization of P-4 NPs at pH 7.4 in HeLa cells. Scale bar: $10 \mu \mathrm{m}$; P-4 NPs and trackers were excited at $488 \mathrm{~nm}$.

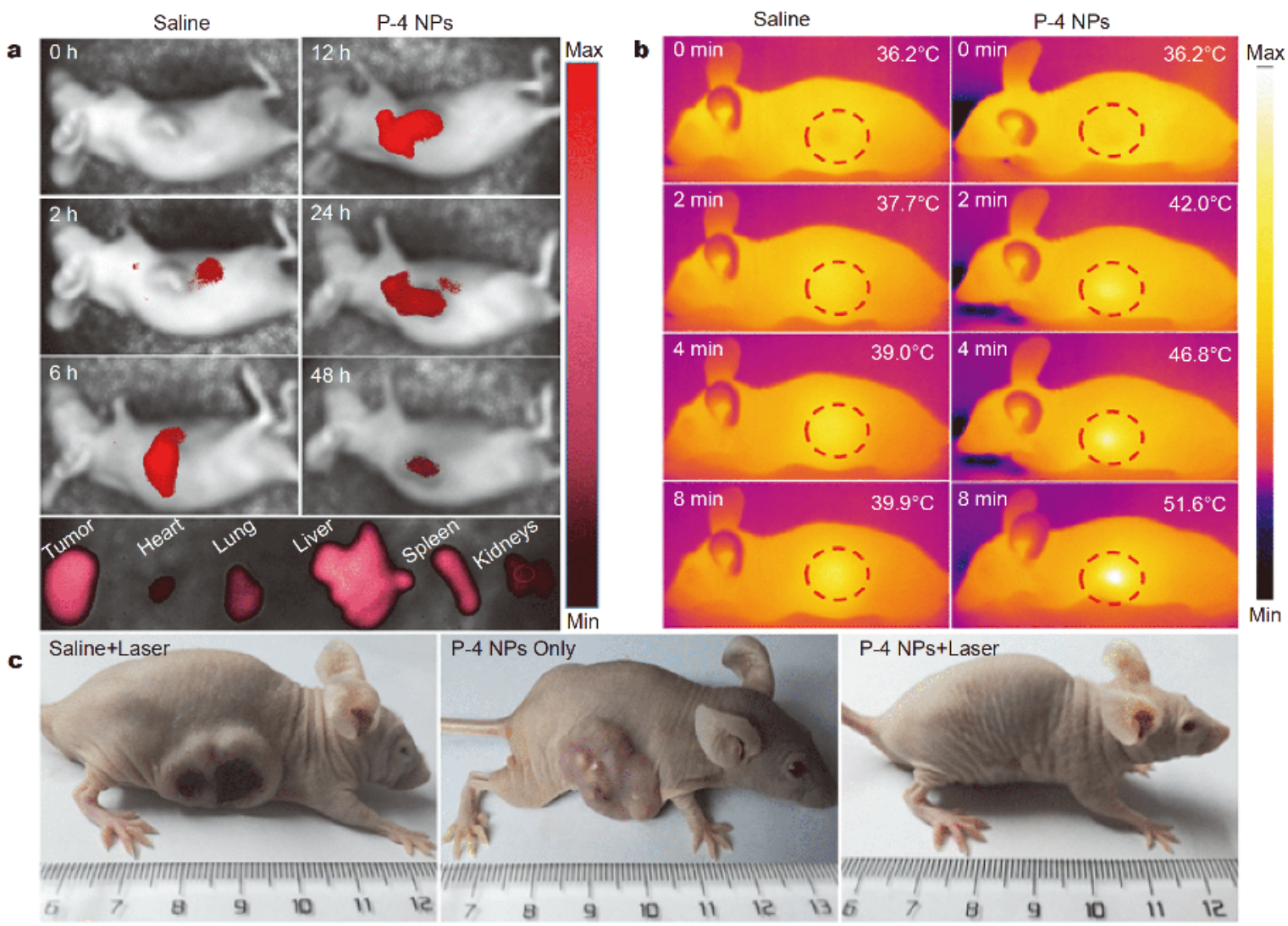

Figure 5 (a) Fluorescence images of tumor and selected organs in tumor-bearing mice after intravenous injection of P-4 NPs. (b) Photothermal images of tumor-bearing mice in the absence and presence of P-4 NPs intravenous injection $\left(80 \mu \mathrm{g} \mathrm{mL} \mathrm{L}^{-1}, 100 \mu \mathrm{L}\right)$. (c) Visual photographs of mice from three groups after 18 days treatment.

bearing nude mice, which were randomly divided into three groups $(n=6)$ : (i) saline with laser irradiation, (ii) P-4 NPs without laser irradiation, (iii) P-4 NPs with laser irradiation as treatment group. Compared with (i) and (ii), tumors in (iii) were totally ablated at the second treatment and all black scars fell off with no recurrence
(18 days, $660 \mathrm{~nm}$, irradiation time: $8 \mathrm{~min}$ ). Nonetheless, all the tumor volumes expanded to $\sim 3,500 \mathrm{~mm}^{3}$ after 18 days in control groups (Fig. S6b). And Fig. 5 c visually shows the therapeutic result for the three groups after 18 days, demonstrating the amplifying phototherapeutic effect and no dark toxicity of P-4 NPs in vivo. Further- 
more, the H\&E staining of tumors for different groups after sacrificing the mice verifies that the cells of two control groups are in good condition compared with the treatment group, further revealing no side effect and great cancer ablation ability of P-4 NPs (Fig. S6d). Besides, the normal body weight change (Fig. S6c) and fine $\mathrm{H} \& \mathrm{E}$ staining of organs (spleen, kidney, lung, heart and liver) (Fig. S7b) can also prove no side effects of P-4 NPs.

\section{CONCLUSIONS}

In conclusion, we have successfully synthesized a $\mathrm{pH}$ responsive and lysosome targeting zinc(II) metalated porphyrin (P-4), which display high NIR absorbance, desired fluorescence quantum yield, excellent singlet oxygen generation ability and superb PTC efficiency. In vitro experiments also prove the strong stability, low dark toxicity and desired photo-toxicity of P-4 NPs. Moreover, P-4 NPs could trigger tumor photo-ablation via single laser illumination in vivo, achieving highly efficient cancer PDT/PTT. In future, the $\mathrm{pH}$-responsive therapy system can also be extended to other phototherapy agent for targeted and efficient cancer therapy.

\section{Received 9 January 2019; accepted 26 March 2019;} published online 12 April 2019

1 Kuimova MK, Botchway SW, Parker AW, et al. Imaging intracellular viscosity of a single cell during photoinduced cell death. Nat Chem, 2009, 1: 69-73

2 Ethirajan M, Chen Y, Joshi P, et al. The role of porphyrin chemistry in tumor imaging and photodynamic therapy. Chem Soc Rev, 2011, 40: 340-362

3 Kennedy LC, Bickford LR, Lewinski NA, et al. A new era for cancer treatment: gold-nanoparticle-mediated thermal therapies. Small, 2011, 7: 169-183

4 Qian C, Yu J, Chen Y, et al. Light-activated hypoxia-responsive nanocarriers for enhanced anticancer therapy. Adv Mater, 2016, 28: $3313-3320$

5 Chen $\mathrm{H}$, Tian J, He W, et al. $\mathrm{H}_{2} \mathrm{O}_{2}$-activatable and $\mathrm{O}_{2}$-evolving nanoparticles for highly efficient and selective photodynamic therapy against hypoxic tumor cells. J Am Chem Soc, 2015, 137: 1539-1547

6 Tian J, Ding L, Xu HJ, et al. Cell-specific and pH-activatable rubyrin-loaded nanoparticles for highly selective near-infrared photodynamic therapy against cancer. J Am Chem Soc, 2013, 135: 18850-18858

7 McDonnell SO, Hall MJ, Allen LT, et al. Supramolecular photonic therapeutic agents. J Am Chem Soc, 2005, 127: 16360-16361

8 Wang Z, Li S, Zhang M, et al. Laser-triggered small interfering RNA releasing gold nanoshells against heat shock protein for sensitized photothermal therapy. Adv Sci, 2017, 4: 1600327

9 Yang Y, Zhu W, Dong Z, et al. 1D coordination polymer nanofibers for low-temperature photothermal therapy. Adv Mater, 2017, 29: 1703588

10 Zhou J, Schmid T, Frank R, et al. PI3K/Akt is required for heat shock proteins to protect hypoxia-inducible factor $1 \alpha$ from pvhlindependent degradation. J Biol Chem, 2004, 279: 13506-13513

11 Lin J, Wang S, Huang P, et al. Photosensitizer-loaded gold vesicles with strong plasmonic coupling effect for imaging-guided photothermal/photodynamic therapy. ACS Nano, 2013, 7: 5320-5329

12 Jang B, Park JY, Tung CH, et al. Gold nanorod-photosensitizer complex for near-infrared fluorescence imaging and photodynamic/photothermal therapy in vivo. ACS Nano, 2011, 5: 10861094

13 Kolishetti N, Dhar S, Valencia PM, et al. Engineering of self-assembled nanoparticle platform for precisely controlled combination drug therapy. Proc Natl Acad Sci USA, 2010, 107: 1793917944

14 Tian B, Wang C, Zhang S, et al. Photothermally enhanced photodynamic therapy delivered by nano-graphene oxide. ACS Nano, 2011, 5: 7000-7009

15 Kim YK, Na HK, Kim S, et al. One-pot synthesis of multifunctional Au@graphene oxide nanocolloid core@shell nanoparticles for raman bioimaging, photothermal, and photodynamic therapy. Small, 2015, 11: 2527-2535

16 Yong Y, Zhou L, Gu Z, et al. $\mathrm{WS}_{2}$ nanosheet as a new photosensitizer carrier for combined photodynamic and photothermal therapy of cancer cells. Nanoscale, 2014, 6: 10394-10403

17 Kim S, Tachikawa T, Fujitsuka M, et al. Far-red fluorescence probe for monitoring singlet oxygen during photodynamic therapy. J Am Chem Soc, 2014, 136: 11707-11715

18 Dougherty TJ, Gomer CJ, Henderson BW, et al. Photodynamic therapy. J Natl Cancer Institute, 1998, 90: 889-905

19 Yu M, Guo F, Wang J, et al. Photosensitizer-loaded pH-responsive hollow gold nanospheres for single light-induced photothermal/ photodynamic therapy. ACS Appl Mater Interfaces, 2015, 7: 17592-17597

20 Tian J, Ding L, Ju H, et al. A multifunctional nanomicelle for realtime targeted imaging and precise near-infrared cancer therapy. Angew Chem Int Ed, 2014, 53: 9544-9549

21 Gatenby RA, Gillies RJ. Why do cancers have high aerobic glycolysis? Nat Rev Cancer, 2004, 4: 891-899

22 Ozlem S, Akkaya EU. Thinking outside the silicon box: Molecular and logic as an additional layer of selectivity in singlet oxygen generation for photodynamic therapy. J Am Chem Soc, 2008, 131: 48-49

23 Weerakkody D, Moshnikova A, Thakur MS, et al. Family of $\mathrm{pH}$ (low) insertion peptides for tumor targeting. Proc Natl Acad Sci USA, 2013, 110: 5834-5839

24 Jiang XJ, Lo PC, Yeung SL, et al. A pH-responsive fluorescence probe and photosensitiser based on a tetraamino silicon(IV) phthalocyanine. Chem Commun, 2010, 46: 3188-3190

25 Ke MR, Ng DKP, Lo PC. A pH-responsive fluorescent probe and photosensitiser based on a self-quenched phthalocyanine dimer. Chem Commun, 2012, 48: 9065-9067

26 Lan M, Zhang J, Zhu X, et al. Highly stable organic fluorescent nanorods for living-cell imaging. Nano Res, 2015, 8: 2380-2389

27 Wang F, Cui X, Lou Z, et al. Switching of the triplet excited state of rhodamine- $\mathrm{C}_{60}$ dyads. Chem Commun, 2014, 50: 15627-15630

28 Venkatesan R, Periasamy N, Srivastava T. Singlet molecular oxygen quantum yield measurements of some porphyrins and metalloporphyrins. Proc Indian Acad Sci-Chem Sci, 1992, 104: 713-722

29 Niedre M, Patterson MS, Wilson BC. Direct near-infrared luminescence detection of singlet oxygen generated by photodynamic therapy in cells in vitro and tissues in vivo. PhotoChem PhotoBiol, 
2002, 75: 382-391

30 Cheng Y, Cheng H, Jiang C, et al. Perfluorocarbon nanoparticles enhance reactive oxygen levels and tumour growth inhibition in photodynamic therapy. Nat Commun, 2015, 6: 8785

31 Zheng R, Wang S, Tian Y, et al. Polydopamine-coated magnetic composite particles with an enhanced photothermal effect. ACS Appl Mater Interfaces, 2015, 7: 15876-15884

32 Tian Q, Jiang $\mathrm{F}$, Zou $\mathrm{R}$, et al. Hydrophilic $\mathrm{Cu}_{9} \mathrm{~S}_{5}$ nanocrystals: a photothermal agent with a $25.7 \%$ heat conversion efficiency for photothermal ablation of cancer cells in vivo. ACS Nano, 2011, 5: 9761-9771

33 Liang $\mathrm{P}$, Wang $\mathrm{Y}$, Wang $\mathrm{P}$, et al. Triphenylamine flanked furandiketopyrrolopyrrole for multi-imaging guided photothermal/ photodynamic cancer therapy. Nanoscale, 2017, 9: 18890-18896

Acknowledgements This work was supported by the National Natural Science Foundation of China (61525402, 61775095 and 21704043), Jiangsu Provincial Key Research and Development Plan (BE2017741), Six Talent Peak Innovation Team in Jiangsu Province (TD-SWYY-009), and the Natural Science Foundation of Jiangsu Province (BK20170990 and $17 \mathrm{KJB} 150020)$.

Author contributions Dong X designed the project. Dong X, Si W and Yang $\mathrm{Z}$ guided the project. Liang $\mathrm{P}$ and Tang $\mathrm{H}$ performed the experiments. Gu R, Xue L, Chen D and Wang W performed some supplemental experiments. Dong X, Si W and Liang P analyzed the results and wrote the manuscript. All authors participated in general discussion of the paper.

Conflict of interest The authors declare that they have no conflict of interest.

Supplementary information The synthesis of $N, N$-dibutyl-4ethynylaniline and supporting results are available in the online version of the paper.

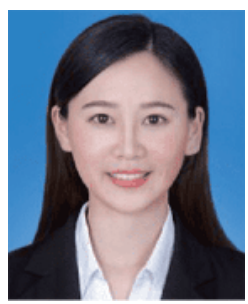

Pingping Liang is studying for a $\mathrm{PhD}$ degree at the Institute of Advanced Materials (IAM), Nanjing Tech University. Her research interest focuses on the cancer phototherapy.

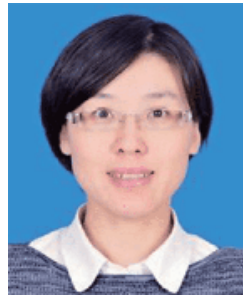

Weili Si received her PhD degree in 2015, from Tohoku University, Japan. Then she joined the Institute of Advanced Materials, Nanjing Tech University as an associate professor. Her current research interests focus on the development of novel photosensitizers and the application in medicinal chemistry.

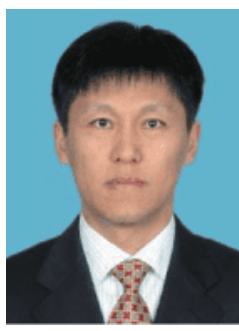

Xiaochen Dong obtained his $\mathrm{PhD}$ degree from Zhejiang University in China in 2007. Then he joined the School of Materials Science and Engineering in Nanyang Technological University as a postdoc. In 2012, he joined the Institute of Advanced Materials, Nanjing Tech University, as a Full Professor. He has published more than 200 papers, including those in Adv. Mater., ACS Nano, JACS, etc. His current research involves biophotonics and bioelectronics.

\section{一种用于增强光动力/光热协同肿瘤治疗的酸性 刺激响应锌(II)金属卟啉化合物}

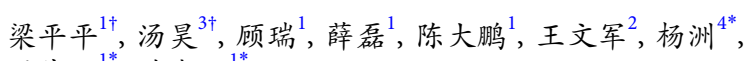
司伟丽 ${ }^{*}$, 董晓臣 ${ }^{1 *}$

摘要 肿瘤酸性微环境是低氧条件下糖酵解引发的, 它能激发体系 的酸性响应系统, 为肿瘤靶向光治疗建立一定的触发机制. 金属化 卟啉结构具有单态氧产率高、苂光成像能力强等优点, 在生物医 学领域得到广泛研究. 本文设计合成了一种具有优异荧光量子产 率 $(67.4 \%)$ 、高单态氧量子产率 $(84.3 \%)$ 和理想光热转换效率 (30.0\%)的酸性响应锌(II)金属卟啉(P-4), 研究了其酸性肿瘤微环境 刺激响应光动力/光热治疗性能. 自组装的P-4纳米粒子可以特异性 地靶向溶酶体亚细胞器位点, 实现二丁胺苯基(DBAP)的质子化过 程且伴随高光毒性; 在660 nm单激光照射下, 肿瘤被完全消除且无 副作用，表明酸刺激响应的P-4纳米粒子可以为肿瘤协同治疗提供 一种新途径. 